\title{
Baseline susceptibility to alpha-cypermethrin in Lutzomyia longipalpis (Lutz \& Neiva, 1912) from Lapinha Cave (Brazil)
}

\author{
Grasielle Caldas DÁvila Pessoa', Josiane Valadão Lopes², Marília Fonseca Rocha³ ${ }^{3}$ Letícia C. Pinheiro', \\ Aline Cristine Luiz Rosa ${ }^{1}$, Érika Monteiro Michalsky² and Edelberto Santos Dias²*
}

\begin{abstract}
Background: Given the increase in cases of visceral leishmaniasis in recent years, associated with the socio-economic impact of this disease, as well as the wide distribution of Lutzomyia longipalpis in Brazil and the likelihood that this vector may develop resistance to insecticides used for control, the Ministry of Health considers as crucial the creation of a network in order to study and monitor the resistance of this vector to insecticides used for control. In this sense, this study aimed: 1) to characterize the susceptibility of L. Iongipalpis from Lapinha Cave (Lagoa Santa, MG - Brazil) to Alfateck SC200 in field bioassays, and 2) to define the susceptibility baseline to alpha-cypermethrin in laboratory bioassays, checking the possibility of using it as susceptibility reference lineage (SRL).

Findings: The field bioassays revealed that the tested population was highly susceptible to alpha-cypermethrin in all time periods with high mortality $(\sim 100 \%)$ in all treated surfaces before six months after spraying. In the laboratory bioassays, the studied population presented $\mathrm{LD}_{50}, \mathrm{LD}_{95}$ and $\mathrm{LD}_{99}$ to $0.78013,10.5580$ and $31.067 \mathrm{mg} / \mathrm{m}^{2}$, respectively. The slope was 1.454121.

Conclusions: The studied population of L. longipalpis was considered as adequate for SRL according criterion recommended by Pan-American Health Organization and has proven susceptibility to tested insecticide in the field. One cannot rule out the possibility of finding populations of L. longipalpis more susceptible to alpha-cypermethrin; therefore, further research is necessary on other populations with potential use as a SRL.
\end{abstract}

Keywords: Lutzomyia longipalpis, Insecticide resistance, Alpha-cypermethrin, Susceptibility reference lineage

\section{Findings}

Lutzomyia longipalpis (Diptera, Psychodidae) has a broad distribution in Brazil and has been recorded in North, Central and South America, from Mexico to Argentina [1]. This phlebotomine sand fly is considered a vector for visceral leishmaniasis (VL), caused by Leishmania (Leishmania) infantum. During the urbanization of visceral leishmaniasis, from 1980 to 2005, 59,129 new cases of VL have been reported in Brazil [2]. In 2013, 3117 new cases of VL were reported in the whole national territory [3].

\footnotetext{
* Correspondence: edel@cpqrr.fiocruz.br

${ }^{2}$ Laboratório de Leishmanioses, Centro de Pesquisas René Rachou, Fundação Oswaldo Cruz, Av. Augusto de Lima 1715, Barro Preto, 29190-002 Belo Horizonte, MG, Brazil

Full list of author information is available at the end of the article
}

There is increasing evidence for the importance of vector control against leishmaniasis, especially for reducing risks of transmission of VL [4-7]; recommended measures include spraying households with pyrethroid insecticides [8]. However, these efforts have not been able to prevent the geographical expansion and the rise in the incidence and lethality of VL in Brazil. Furthermore, although most sand fly species remain susceptible to all of the major classes of insecticides in the world, there is increasing evidence that some phlebotomine sand flies may be developing insecticide resistance [9]. In many vector species such as Neotropical phlebotomine sand flies, the occurrence of insecticide resistance is still poorly studied. Insecticide resistance has not yet been demonstrated in L. longipalpis but there are some indications of its occurrence in this specie $[10,11]$. 
Therefore, considering the increase in VL cases in recent years in Brazil and the consequent socio-economic impact caused by this disease, the wide distribution of L. longipalpis in the country and the likelihood that this vector may develop resistance to insecticides used for control, the Ministry of Health considers as crucial the creation of a network in order to study and monitor the resistance of this vector to insecticides [12]. In response to this need, this study aimed to characterize the susceptibility of L. longipalpis from Lapinha Cave (Lagoa Santa, MG - Brazil) within a timeline, to the insecticide currently being used for control of phlebotomine sand flies in the country through field bioassays, as well as define the susceptibility baseline of alpha-cypermethrin in laboratory bioassays; checking the possibility of using it as a susceptibility reference lineage (SRL).

The phlebotomine sand flies were collected from Lapinha cave (licence $\mathrm{n}^{\circ}$ SISBIO 18728-1). HP traps [13] were used for overnight indoor insect collection. After collection, the insects were allowed to settle for a few hours for conditioning during which time they were supplied with $10 \%$ sucrose solution. In this sense, we identify $30 \%$ of the specimens per capture, as an internal control. The species identifications adopted in our laboratory takes into account the taxonomic keys available in Young and Ducan [1], as well as comparison with specimens deposited at the Phlebotomine Sand fly Reference Collection at CPqRR/Fiocruz.

Field bioassays were carried out in Montes Claros, MG. The residents voluntarily signed a Statement of Informed Consent. A sample was formed with three domestic units (DUs), comparable in terms of type of surface (adobe with plaster, adobe without plaster, wood) and environmental characteristics, treated with alphacypermethrin $20 \%$-Alfatek ${ }^{\circledR}$ SC'(Rogama, Brazil). This is the insecticide currently used by the Ministry of Health of Brazil for phlebotomine sand fly control, with residual effect expected for up to 6 months. Spraying was carried out by agents of endemic diseases in the region, as recommended by the Ministry of Health. A Guarani hand sprayer was used attached to a Tee-jet 8002 nozzle. Testing was performed from July to December, 2014. At $1,30,60,90,120$ and 150 days after spraying the DUs, 30 females (fasting; parental generation) were submitted to wall surface tests in plastic cones for $1 \mathrm{~h}$. Then, the phlebotomine sand flies were transferred to insecticide-free bottles and kept in an insectary with temperature and humidity controlled $\left(25{ }^{\circ} \mathrm{C} \pm 1{ }^{\circ} \mathrm{C}\right.$, $60 \% \pm 10 \% \mathrm{RU})$. Three cones were exposed inside the intradomicile and another three cones around in the peridomicile, of each surface type, per treated DU (experimental DUs - number 1,2,3). The insects of the control group were exposed to insecticide-free surfaces of the intradomicile and peridomicile (control DU - number 4). The mortality was recovered $24 \mathrm{~h}$ after phlebotomine sand flies exposition. A specimen was classified as dead if it was immobile or unable to stand or fly in a coordinated way [14].

In the laboratory, the insects were subjected to impregnated paper with ten different alpha-cypermethrin (BASF, Brazil) concentrations (0.1 to $7.5 \mathrm{mg}$ i.a. $/ \mathrm{m}^{2}$ ), for one hour. For control tests, insects were exposed to impregnated paper prepared only with vaseline oil and chloroform [15]. At least three replicates of 30 females were tested per concentration. The mortality was recovered $24 \mathrm{~h}$ after insects' exposition. A specimen was classified as dead if it was immobile or unable to stand or fly in a coordinated way [13]. Data from dose-response tests were analyzed using the PROBIT program [16]. The slope and the lethal doses required to kill $50 \%\left(\mathrm{LD}_{50}\right), 95 \%\left(\mathrm{LD}_{95}\right)$ and $99 \%$ $\left(\mathrm{LD}_{99}\right)$ of treated individuals were estimated. During the test, the temperature and humidity were controlled $\left(25{ }^{\circ} \mathrm{C} \pm 1{ }^{\circ} \mathrm{C}, 60 \% \pm 10 \% \mathrm{RU}\right)$.

Results obtained in the field bioassays revealed that the tested population was highly susceptible to alphacypermethrin during all the time period. The mortality was close to $100 \%$ during the six months (Table 1). The comparison of mortality observed in control and experimental DUs by the Kruskal-Wallis test revealed a significant difference between at least two of the four DUs $\left(p=2.2 \times 10^{-16}\right)$. The Mann-Whitney post-test showed a difference only between the control DU and experimental DUs, proving that the mortality of phlebotomine specimen was related to the presence of the insecticide on the timeline, in the intradomicile and peridomicile, in all types of surface tested. There was no statistical difference in the mortality rate observed in the intradomicile and peridomicile between different surfaces and between different experimental DUs.

The choice of the susceptibility reference lineage is a critical and fundamental step that precedes bioassays that check insect resistance to insecticides. The Pan-American Health Organization (PAHO) [17] defined a SRL as a strain with more than five generations in the laboratory (without contact with insecticides and inclusion of external material), and/or one collected from an area that has never been treated with insecticides. The phlebotomine sand flies from Lapinha Cave have met this criterion, because this region has had little anthropic interference; thus, they had not been subjected to chemical control. The high susceptibility of this population of $L$. longipalpis to alpha-cypermethrin was demonstrated in field bioassays in which high mortality was observed throughout the monitoring period.

In the laboratory bioassays, the studied population presented $\mathrm{LD}_{50}, \mathrm{LD}_{95}$ and $\mathrm{LD}_{99}$ to $0.78013,10.5580$ and $31.067 \mathrm{mg} / \mathrm{m}^{2}$, respectively. The slope was 1.454121 . Such data is unprecedented in the literature and lethal doses were defined for the first time in studies with 
Table 1 Mortality of L. longipalpis in response to exposure on different surfaces impregnated with alpha-cypermethrin $20 \%$

\begin{tabular}{|c|c|c|c|c|c|c|c|c|c|c|c|c|c|}
\hline \multirow{3}{*}{$\begin{array}{l}\text { Domestic } \\
\text { Unit (DU) }\end{array}$} & \multirow{3}{*}{$\begin{array}{l}\text { Surfaces } \\
\text { Treated }\end{array}$} & \multicolumn{4}{|c|}{1 day after spraying } & \multicolumn{4}{|c|}{30 days after spraying } & \multicolumn{4}{|c|}{60 days after spraying } \\
\hline & & \multicolumn{2}{|c|}{ Intradomicile } & \multicolumn{2}{|c|}{ Peridomicile } & \multicolumn{2}{|c|}{ Intradomicile } & \multicolumn{2}{|c|}{ Peridomicile } & \multicolumn{2}{|c|}{ Intradomicile } & \multicolumn{2}{|c|}{ Peridomicile } \\
\hline & & Tested & Dead (\%) & Tested & Dead (\%) & Tested & Dead (\%) & Tested & Dead (\%) & Tested & Dead (\%) & Tested & Dead (\%) \\
\hline \multirow[t]{4}{*}{$\mathrm{DU} 1^{\mathrm{a}}$} & Wood & 30 & $28(93)$ & 30 & $23(77)$ & 30 & $30(100)$ & 30 & $30(100)$ & 30 & $30(100)$ & 30 & $30(100)$ \\
\hline & Adobe with plaster & 30 & $30(100)$ & 30 & $30(100)$ & 30 & $30(100)$ & 30 & $30(100)$ & 30 & $30(100)$ & 30 & $30(100)$ \\
\hline & Adobe without plaster & 30 & $30(100)$ & 30 & $29(97)$ & 30 & $30(100)$ & 30 & $30(100)$ & 30 & $30(100)$ & 30 & $27(90)$ \\
\hline & Wood & 30 & $29(97)$ & 30 & $29(97)$ & 30 & $30(100)$ & 30 & $30(100)$ & 30 & $30(100)$ & 30 & $30(100)$ \\
\hline \multirow[t]{3}{*}{$\mathrm{DU} 2^{\mathrm{a}}$} & Adobe with plaster & 30 & $30(100)$ & 30 & $30(100)$ & 30 & $30(100)$ & 30 & $30(100)$ & 30 & $30(100)$ & 30 & $30(100)$ \\
\hline & Adobe without plaster & 30 & $30(100)$ & 30 & $30(100)$ & 30 & $29(97)$ & 30 & $27(90)$ & 30 & $28(93)$ & 30 & $30(100)$ \\
\hline & Wood & 30 & $30(100)$ & 30 & $30(100)$ & 30 & $30(100)$ & 30 & $30(100)$ & 30 & $30(100)$ & 30 & $30(100)$ \\
\hline \multirow[t]{2}{*}{$\mathrm{D} \cup 3^{\mathrm{a}}$} & Adobe with plaster & 30 & $30(100)$ & 30 & $30(100)$ & 30 & $30(100)$ & 30 & $30(100)$ & 30 & $30(100)$ & 30 & $30(100)$ \\
\hline & Adobe without plaster & 30 & $30(100)$ & 30 & $30(100)$ & 30 & $30(100)$ & 30 & $25(83)$ & 30 & $30(100)$ & 30 & $27(90)$ \\
\hline \multirow[t]{3}{*}{ DU $4^{b}$} & Wood & 30 & $1(3)$ & 30 & $0(0)$ & 30 & $0(0)$ & 30 & $0(0)$ & 30 & $0(0)$ & 30 & $0(0)$ \\
\hline & Adobe with plaster & 30 & $0(0)$ & 30 & $0(0)$ & 30 & $0(0)$ & 30 & $0(0)$ & 30 & $0(0)$ & 30 & $0(0)$ \\
\hline & Adobe without plaster & 30 & $0(0)$ & 30 & $0(0)$ & 30 & $0(0)$ & 30 & $0(0)$ & 30 & $0(0)$ & 30 & $0(0)$ \\
\hline
\end{tabular}


Table 1 Mortality of L. longipalpis in response to exposure on different surfaces impregnated with alpha-cypermethrin $20 \%$

\begin{tabular}{|c|c|c|c|c|c|c|c|c|c|c|c|c|}
\hline \multirow{3}{*}{$\begin{array}{l}\text { Domestic } \\
\text { Unit (DU) }\end{array}$} & \multicolumn{4}{|c|}{90 days after spraying } & \multicolumn{4}{|c|}{120 days after spraying } & \multicolumn{4}{|c|}{150 days after spraying } \\
\hline & \multicolumn{2}{|c|}{ Intradomicile } & \multicolumn{2}{|c|}{ Peridomicile } & \multicolumn{2}{|c|}{ Intradomicile } & \multicolumn{2}{|c|}{ Peridomicile } & \multicolumn{2}{|c|}{ Intradomicile } & \multicolumn{2}{|c|}{ Peridomicile } \\
\hline & Tested & Dead (\%) & Tested & Dead (\%) & Tested & $\overline{\text { Dead }(\%)}$ & Tested & Dead (\%) & Tested & Dead (\%) & Tested & Dead (\%) \\
\hline \multirow[t]{4}{*}{$\overline{D U} 1^{a}$} & 30 & $30(100)$ & 30 & $29(97)$ & 30 & $30(100)$ & 30 & $29(97)$ & 30 & $30(100)$ & 30 & $29(97)$ \\
\hline & 30 & $30(100)$ & 30 & $28(93)$ & 30 & $30(100)$ & 30 & $27(90)$ & 30 & $30(100)$ & 30 & $29(97)$ \\
\hline & 30 & $28(93)$ & 30 & $25(83)$ & 30 & $30(100)$ & 30 & $29(97)$ & 30 & $30(100)$ & 30 & $30(100)$ \\
\hline & 30 & $29(97)$ & 30 & $29(97)$ & 30 & $29(97)$ & 30 & $30(100)$ & 30 & $30(100)$ & 30 & $28(93)$ \\
\hline \multirow[t]{3}{*}{$\mathrm{DU} 2^{\mathrm{a}}$} & 30 & $30(100)$ & 30 & $30(100)$ & 30 & $30(100)$ & 30 & $28(93)$ & 30 & $30(100)$ & 30 & $30(100)$ \\
\hline & 30 & $29(97)$ & 30 & $29(97)$ & 30 & $30(100)$ & 30 & $10(33)$ & 30 & $28(93)$ & 30 & $28(93)$ \\
\hline & 30 & $30(100)$ & 30 & $29(97)$ & 30 & $30(100)$ & 30 & $29(97)$ & 30 & 30 (100) & 30 & $29(97)$ \\
\hline \multirow[t]{2}{*}{$\mathrm{D} \cup 3^{\mathrm{a}}$} & 30 & $30(100)$ & 30 & $29(97)$ & 30 & $29(97)$ & 30 & $29(97)$ & 30 & $30(100)$ & 30 & $30(100)$ \\
\hline & 30 & $29(97)$ & 30 & $30(100)$ & 30 & $30(100)$ & 30 & $30(100)$ & 30 & $30(100)$ & 30 & $30(100)$ \\
\hline \multirow[t]{3}{*}{$\mathrm{DU} 4^{\mathrm{b}}$} & 30 & $0(0)$ & 30 & $0(0)$ & 30 & $0(0)$ & 30 & $0(0)$ & 30 & $0(0)$ & 30 & $0(0)$ \\
\hline & 30 & $0(0)$ & 30 & $0(0)$ & 30 & $0(0)$ & 30 & $0(0)$ & 30 & $0(0)$ & 30 & $0(0)$ \\
\hline & 30 & $0(0)$ & 30 & $0(0)$ & 30 & $0(0)$ & 30 & $1(3)$ & 30 & $0(0)$ & 30 & $0(0)$ \\
\hline
\end{tabular}

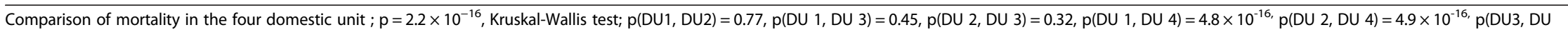
4) $=2.8 \times 10^{-16}$, Kruskal-Wallis post-hoc tests (Mann-Whitney tests considering correction for multiple tests)

${ }^{\mathrm{a} E x p e r i m e n t a l}$ group

${ }^{\mathrm{b}} \mathrm{Control}$ group 
phlebotomine sand flies. The LDs defined for the SRL have a direct and immediate use if this population is used as SRL for studies with L. longipalpis. The $\mathrm{LD}_{99}$ of SRL is fundamental for defining a diagnostic dose (DD) a tool that allows the distinction of the field population vigor against the SRL, killing the most susceptible specimens and the minimally resistant specimens. In studies with triatomines, the WHO [18] recommends the use of $\mathrm{DD}=1 \times \mathrm{LD}_{99}$ and, for mosquitoes, $2 \times \mathrm{LD}_{99}$ [15]. Because research on phlebotomine sand flies is still incipient, further studies are required in order to adapt this methodology to biological/physiological characteristics of $L$. longipalpis, thus defining cutoff points that are used to foster understanding of susceptibility and resistance to insecticides.

The other LDs characterized for SRL (e.g. $\mathrm{LD}_{50}$ and $\mathrm{LD}_{95}$ ) may be used in the initial design of the dose-response bioassays to study field populations of L. longipalpis. In addition, knowledge of the $\mathrm{LD}_{50}$ for $\mathrm{SRL}$ is fundamental for calculation of the resistance ratio of $50 \%$ $\left(R R_{50}\right)$. This indicator, calculated by dividing the $\mathrm{LD}_{50}$ of each field population by the $\mathrm{LD}_{50}$ value of the SRL, allows the susceptibility status classification of the study field population. Based on this classification, actions can be taken for vector control strategies in the field. According to PAHO [17] Triatominae populations with $R R>5$ are considered resistant to the insecticide tested, whereas populations of Aedes aegypti with $\mathrm{RR}>3$ are considered resistant [19]. For phlebotomine sand flies, this information does not exist, which justifies the need for a screening of various populations of $L$. longipalpis in the laboratory and in the field bioassays, simultaneously, to define such cut-off points.

The population from Lapinha Cave has been characterized as one of the putative sibling species of L. longipalpis [20], and it was considered as appropriate as a SRL for laboratory bioassays because: 1 ) it meets the criteria for SRL, recommended by PAHO and 2) it shows insecticide susceptibility in the field on the timeline confirmed in laboratory bioassays. However, one cannot rule out the possibility of finding more susceptible populations of L. longipalpis. This has already been verified with triatomine studies [21]. This fact reinforces the need for further research on other populations and putative sibling species of $L$. longipalpis with potential to be used as SRL, such as those from Jacobina (Bahia, Brazil) and Espírito Santo do Pinhal (São Paulo, Brazil) [12, 20].

\section{Competing interests}

The authors declare that they have no competing interests.

\section{Authors' contributions}

All authors have contributed substantially to this study. GCDP and ESD conceived and designed the experiments. MR contributed biologic material. GCDP, JLV, EMM, ACLR, MFR and ESD performed the experiments. GCDP and
LPC analyzed the data. GCDP and ESD wrote the manuscript. All authors read and approved the final manuscript.

\section{Acknowledgements}

This study was supported by the Conselho Nacional de Desenvolvimento Científico e Tecnológico (CNPq), Centro de Pesquisa Rene Rachou (CPqRR), Fundação Oswaldo Cruz (FIOCRUZ), Secretaria de Vigilância em Saúde (SVS) and Ministério da Saúde (MS) - Brazil. We would also like to thank to BASF Brazil for providing the insecticide used in laboratory bioassays and Msc. Newmar Pinto Marliéri for the support provided in the process of paper sheet impregnation. Special thanks to Dra. Liléia Diotaiuti for permission to perform bioassays in Laboratório de Referência em Triatomíneos e Epidemiologia da Doença de Chagas - CPqRR/FIOCRUZ Minas, also for valuable suggestions and comments.

\section{Author details}

'Laboratório de Referência em Triatomíneos e Epidemiologia da Doença de Chagas, Centro de Pesquisas René Rachou, Fundação Oswaldo Cruz, Belo Horizonte, MG, Brazil. " Laboratório de Leishmanioses, Centro de Pesquisas René Rachou, Fundação Oswaldo Cruz, Av. Augusto de Lima 1715, Barro Preto, 29190-002 Belo Horizonte, MG, Brazil. ${ }^{3}$ Centro de Controle de Zoonoses de Montes Claros, Montes Claros, MG, Brazil.

Received: 18 June 2015 Accepted: 8 September 2015

Published online: 17 September 2015

\section{References}

1. Young DG, Duncan MA. Guide to the identification and geographic distribution of Lutzomyia sandflies in Mexico, the West Indies, Central and South America (Diptera: Psychodidae). Mem Am Entomol Inst. 1994;54(1):881.

2. Maia-Elkloruty ANS, Alves WA, Sousa-Gomes ML, Sena JM, Luna EA. Visceral leishmaniasis in Brazil: trends and challenges. Cad Saude Publ, Rio de Janeiro. 2008;24(12):2941-7.

3. Brasil. Ministério da Saúde. Sistema de Informação de Agravos de Notificação. Leishmaniose visceral: casos notificados. http:// dtr2004.saude.gov.br/sinanweb Accessed 13 Sept 2015.

4. Alexander B, Usma MC, Cadena H, Quesada BL, Solarte Y, Roa W, et al. Evaluation of deltamethrin-impregnated bednets and curtains against phlebotomine sandflies in Valle de la Cauca, Colombia. Med Vet Entomol. 1995;9:279-83.

5. Nadin A, Motabar M, Houshmand B, Keyghobady K, Aflatonian MR. Evaluation of pyrethroid impregnated bednets for control of anthroponotic cutaneous leishmaniasis in Bam (Islamic Republic of Iran). WHO documents WHO/LEISH/95.37. WHO, Geneva; 1995.

6. Tayeh A, Jalouk L, Al-Khiami AM. A cutaneous leishmaniasis control trial using pyrethroid-impregnated bednets in villages near Aleppo, Syria. WHO document WHO/LEISH/97.41. WHO, Geneva; 1997.

7. Reyburn H, Ashford R, Mohsen M, Hewitt S, Rowland M. Randomized controlled Trial insecticide-treated bednets and chaddars or top sheets and residual spraying of interior rooms for the prevention of cutaneous leishmaniasis in Kabul, Afghanistan. Trans R Soc Trop Med Hyg. 2000;94:361-6

8. Brasil. Ministério da Saúde. Secretaria de Vigilância em Saúde. Departamento de Vigilância Epidemiológica. Manual de controle da leishmaniose visceral: normas e manuais técnicos. Brasília: Ministério da Saúde; 2006.

9. Alexander B, Maroli M. Control of Phlebotomine sandflies. Med Vet Entomol. 2003;17:1-18.

10. Falcão $\mathrm{AR}$, Pinto $C T$, Ferreira Gontijo CM. Susceptibility of Lutzomyia longipalpis to deltamethrin. Mem Inst Oswaldo Cruz. 1988;83:395-6.

11. Mazzarri MB, Feliciangeli MD, Maroli M, Hernandez A, Bravo A. Susceptibility of Lutzomyia longipalpis (Diptera: Psychodidae) to selected insecticides in na endemic focus of visceral leismaniasis in Venezuela. J American Mosquito Control Association. 1997;13:335-41.

12. Brasil. Ministério da Saúde. I Oficina da implantação da "Rede de Monitoramento de Flebotomíneos a Inseticidas". Resumo executivo, Ministério da Saúde, Secretaria de Vigilância em Saúde, Brazilian Ministry of Health. 2012. p. 4.

13. Pugedo H, Barata RA, França-Silva JC, Silva JC, Dias ES. HP: um modeloaprimorado de armadilha luminosa de sucção para a captura de pequenos insetos. Rev Soc Bras Med Trop. 2005;38(1):70-2. 
14. WHO. Instructions for determining the susceptibility or resistance of blackflies, sandflies and biting midges to insecticides. WHO/NBC/81.810 1981; p.1-6. WHO, Geneva.

15. World Health Organization. Criteria and meaning of testes for determining the susceptibility or resistance of insects to insecticides. VBC/81.6. 1981.

16. Finney JD. Probit analysis: statistical treatment of the sigmoid response curve. Cambridge: Cambridge University Press; 1971.

17. Organización Panamericana de la Salud (PAHO). II Reunion técnica latinoamericana de monitoreo de resistência a insecticidas em triatominos vectores de Chagas, OPS. Panamá: PAHO; 2005.

18. World Health Organization (WHO). Taller sobre la evaluación de efecto insecticida sobre triatominos. Workshop on the insecticide effect evaluation in triatominos. Acta Toxicol Argentina. 1994:2:29-33.

19. Brasil. Ministério da Saúde. Secretaria de Vigilância em Saúde. Coordenação geral do Programa Nacional do Controle de Dengue. Reunião Técnica para discutir o status de resistência de Aedes aegypti aos inseticidas. Brasília: Ministério da Saúde; 2006. p. 2

20. Lins RM, Souza NA, Brazil RP, Maingon RD, Peixoto AA. Fixed differences in the paralytic gene define two lineages within the Lutzomyia longipalpis complex producing different types of courtship songs. PLoS One. 2012; $7:$ :44323.

21. Pessoa GCD, Dias LS, Diotaiuti L. Deltamethrin pyrethroid susceptibility characterization of Triatoma sordida Stal, 1859 (Hemiptera:Reduviidae) populations in the Northern Region of Minas Gerais, Brasil. Rev Soc Bras Med Trop. 2014;47(4):426-9

\section{Submit your next manuscript to BioMed Central and take full advantage of:}

- Convenient online submission

- Thorough peer review

- No space constraints or color figure charges

- Immediate publication on acceptance

- Inclusion in PubMed, CAS, Scopus and Google Scholar

- Research which is freely available for redistribution 